\title{
Effect of Nanofillers in Tyre Inner Liner Rubber Compound for Better Air Impermeability
}

\author{
Koushik Banerjee $^{\ddagger}$, Sanjay Kumar Bhattacharyya ${ }^{\ddagger}$, Rabindra Mukhopadhyay $^{\ddagger}$, Abhijit Bandyopadhyay $^{1^{*}}$ \\ ${ }^{\ddagger}$ Hari Shankar Singhania Elastomer and Tyre research Institute, Plot No. 437, Hebbal Industrial Area, Mysore-570016, \\ Karnataka, India \\ ${ }^{1}$ Department of Polymer Science and Technology, University of Calcutta 92, APC Road, Calcutta 700009, India
}

*Corresponding Author: Abhijit Bandyopadhyay

Email:abpoly@caluniv.ac.in

DOI: 10.29322/IJSRP.11.10.2021.p11817

http://dx.doi.org/10.29322/IJSRP.11.10.2021.p11817

\begin{abstract}
The present work explains the influential effect of nanofillers for improving the barrier properties of a tyre inner liner. The study has revealed that organoclay Cloisite 30B when explored in a TBR inner liner recipe containing Bromobutyl rubber (BIIR), shows significant improvement in barrier properties without affecting the cure characteristics and mechanical properties of the compound. At $4 \mathrm{phr}$ dosage, the improvement in air retention is approximately $12 \%$. The experiment has also demonstrated that to maintain the air impermeability same as that of the control inner liner, thickness can be reduced up to $56 \%$ while using experimental recipes containing organoclay.
\end{abstract}

Keywords: Organoclay, Bromobutyl rubber, Dispersion, Air impermeability

\section{INTRODUCTION}

Elastomer nanocomposite reinforced with low volume fraction of nanofillers have created great interest due to their fascinating properties. Nanofillers such as layered silicate clays [1], carbon nano tubes [2], calcium carbonate [3], metal oxides [4] or silica nano particle [5] into elastomer improves significantly the properties such as mechanical, thermal, dynamic mechanical, barrier, flame retardant etc. Typically, nanocomposites are materials having filler size in the nanometer size range, at least in one dimension. Nanofillers have a high specific surface area. The specific surface area is one of the reasons for the reinforcement of the nanofillers even at very low filler loading $(<10 \mathrm{wt} \%)$ [6]. In conventional composites, properties are predominated by the bulk properties of both filler and matrix whereas, in nanocomposites, the properties of the material are more glued towards the interface.

The nanofillers used in polymer nanotechnology are usually, having different shapes and on that basis can broadly be categorized into the following classes such as, spherical or cubical nanofillers like nano silica, nano $\mathrm{CaCO}_{3}$, etc.; rod or fiber shaped nanofillers like carbon nanotubes, carbon nanofiber, etc.; sheet or platelet shaped nanofillers like layered silicates such as smectite group of clays, synthetic mica etc. The silicates are the largest, the most interesting and the most complicated class of minerals by far. One of the most common layered silicates is montmorillonite (MMT) [7]. In montmorillonite, many varieties of clay are aluminosilicates with a layered structure which consists of silica $\left(\mathrm{SiO}_{4}{ }^{4-}\right)$ tetrahedral sheets bonded to alumina $\left(\mathrm{AlO}_{6}{ }^{9}\right)$ octahedral ones. Montmorillonite can absorb water between the charged layers. In order to make MMT compatible with organic polymers, the alkali ions were replaced by $\omega$-amino 
acid hydrochloride salt and organic surfactants, such as alkylammonium and arylphosphonium ion as shown in Fig. 1. The surfactant provides a hydrophobic nature to the silicate surface, which causes the layers to become organophilic and such clay is known as organoclay [8]. These surfactant molecules increase the interlayer distance and improve the compatibility with the polymer.

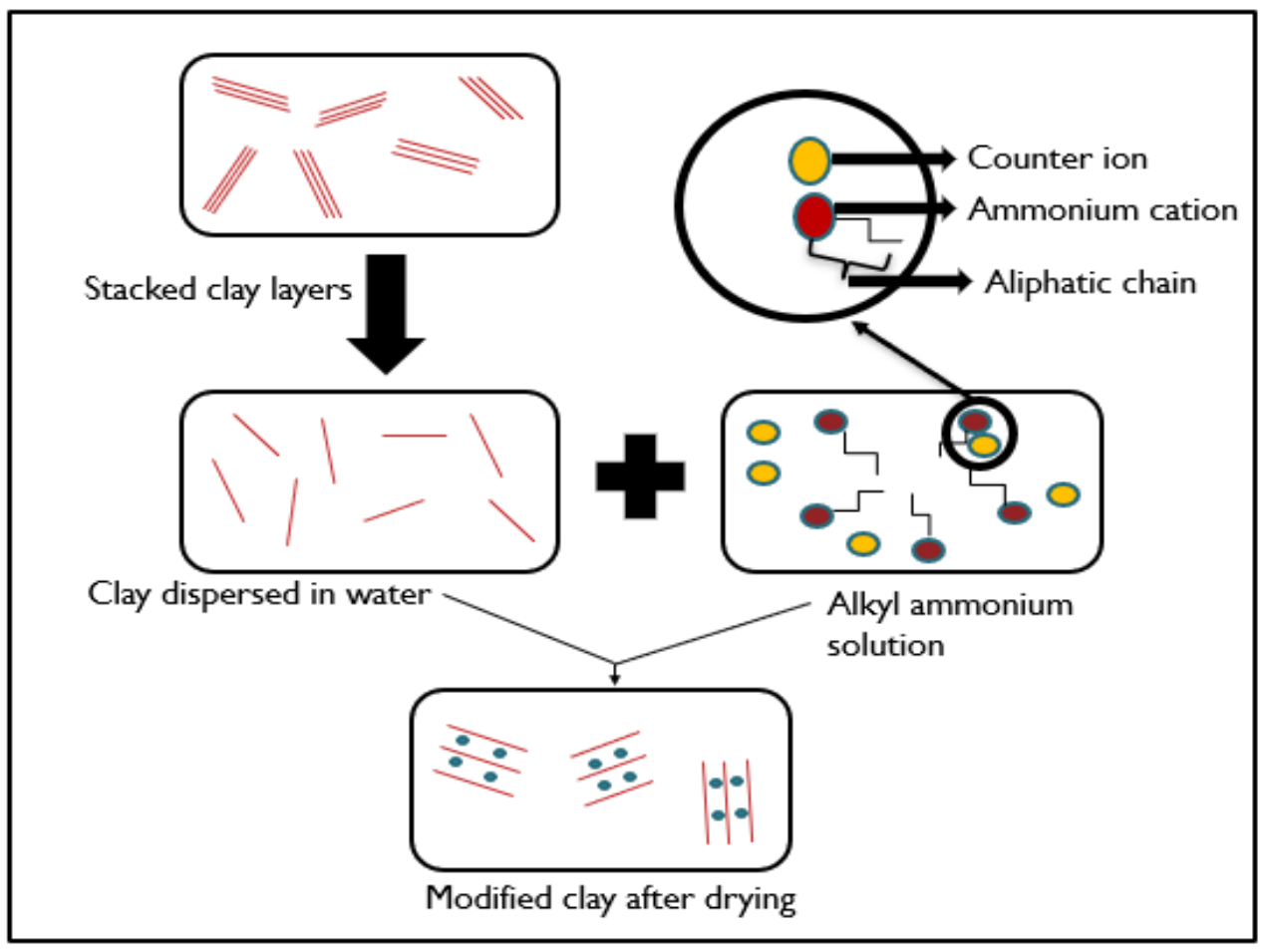

Figure 1: Modification of nanoclays with organic amines

The purpose of a tubeless tyre inner liner is air retention. In conventional composites, air molecules can easily pass through, whereas they take more time to pass through the nanocomposites. It is believed that the air travelling path formed by the nanoclays are 'zigzag', whereas in convectional composites, the path is straight, as shown in Fig. 2. Therefore, in this scope of experiment, two different types of nanoclays such as Sepiolite (unmodified clay) and Cloisite 30B (modified clay) were experimented in a Truck and Bus Radial (TBR) inner liner recipe and the properties of the nanoclay containing experimental compounds were compared against a control recipe without having nanoclay. Based on the improvements in the air impermeabilities, a possible gauge reduction analysis was done in order maintain the air retention same as that of the control compound.

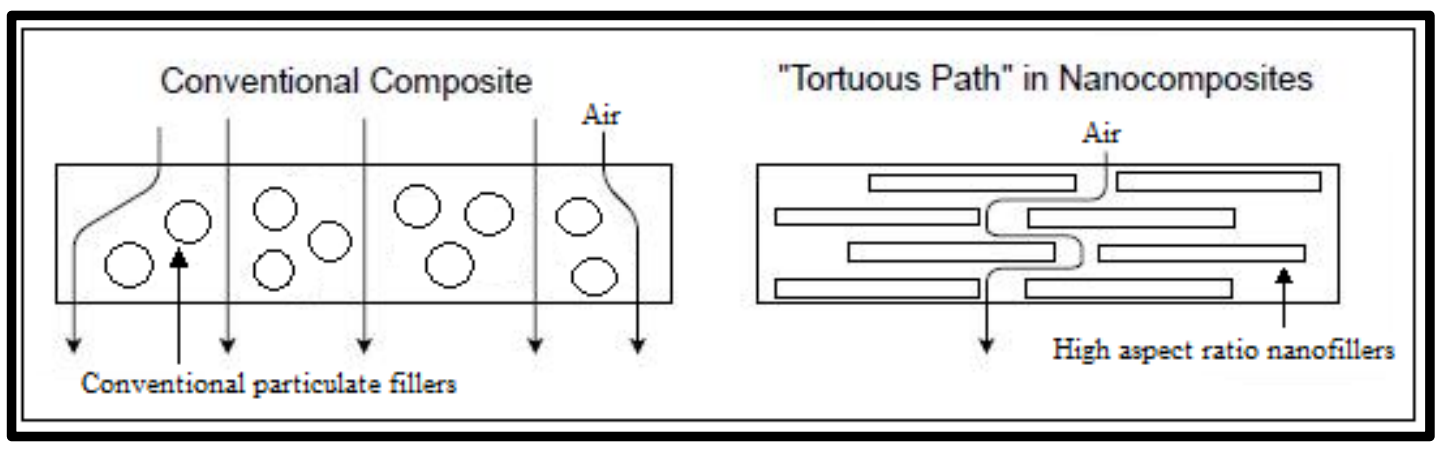

Figure 2: Comparison of air travelling path in nanocomposite with conventional composite 


\section{EXPERIMENTAL SECTION}

\subsection{Raw Materials:}

Bromobutyl rubber (BIIR-2222) of low Mooney grade (Mooney Viscosity $32 \mathrm{MU}$ ) was procured from Exxon Mobil Chemical Company, USA. Natural rubber, SMR 20 (Mooney Viscosity $85 \mathrm{MU}$ ) having a dirt content of $0.2 \%$ (maximum) was purchased from Malaysia. Sepiolite which is a Magnesium silicate clay, was obtained from SKKU minerals, India. Tallow modified Montmorillonite based organoclay (OMMT), Cloisite 30B, was procured from the Southern Clay, India. The Carbon black, N660 (nitrogen surface area $30.5 \mathrm{~m}^{2} / \mathrm{gm}, \mathrm{OAN}=90.5 \mathrm{cc} / 100 \mathrm{gm}$ ), was supplied by Hi-Tech Carbon, India. The compounding ingredients such as zinc oxide (ZincO-India), Stearic acid (Godrej Soap Limited, India), Low PCA oil (Raj Petro, Silvasa), Coumarone-Indene Resin (CI Resin) (Bombay chemicals, Pune), Soluble Sulfur (Jain Chemicals Ltd., India) and MBTS (dibenzothiazole disulfide, NOCIL, Thane), were procured from indigenous sources and were used as received.

\subsection{Rubber Compound Preparation:}

To study the elastomer-nanoclay interaction and intercalation/exfoliation, the clays were explored in model formulations of TBR and PCR inner liners. The formulations are shown in Table 1.

Table 1: Compound Formulations of TBR Inner liner

\begin{tabular}{|c|c|c|c|c|c|}
\hline Ingredients (phr)* & Control & SP-2 & $\mathbf{3 0 B - 2}$ & SP-4 & 30B-4 \\
\hline BIIR & 100.00 & 100.00 & 100.00 & 100.00 & 100.00 \\
\hline Stearic acid & 2.00 & 2.00 & 2.00 & 2.00 & 2.00 \\
\hline N660 & 60.00 & 60.00 & 60.00 & 60.00 & 60.00 \\
\hline Sepiolite & - & 2.00 & - & 4.00 & - \\
\hline Cloisite 30B & - & - & 2.00 & - & 4.00 \\
\hline Low PCA oil & 5.00 & 5.00 & 5.00 & 5.00 & 5.00 \\
\hline CI Resin & 7.00 & 7.00 & 7.00 & 7.00 & 7.00 \\
\hline MBTS & 1.20 & 1.20 & 1.20 & 1.20 & 1.20 \\
\hline & & & & & \\
\hline Soluble Sulfur & 0.40 & 0.40 & 0.40 & 0.40 & 0.40 \\
\hline Zinc oxide & 3.10 & 3.10 & 3.10 & 3.10 & 3.10 \\
\hline Total & $\mathbf{1 7 8 . 7 0}$ & $\mathbf{1 8 0 . 7 0}$ & $\mathbf{1 8 0 . 7 0}$ & $\mathbf{1 8 2 . 7 0}$ & $\mathbf{1 8 2 . 7 0}$ \\
\hline
\end{tabular}

The mixing was performed in a Haake Rheomix laboratory scale mixer (Thermo scientific, USA) equipped with 4-wing rotor and with a chamber volume of $370 \mathrm{~cm}^{3}$.

The masterbatches were mixed at a TCU setting of $90^{\circ} \mathrm{C}$ and at $60 \mathrm{rpm}$ and the final batches were mixed at $30 \mathrm{rpm}$ and $70^{\circ} \mathrm{C} \mathrm{TCU}$ setting. The mixing duration was 300s. For experimental compounds, initial 240s rubber-clay pre-mastication [9] was given as significant enhancement was observed. Masterbatch discharge temperature was kept in the range of $115-120^{\circ} \mathrm{C}$. The final batches were discharged between $85-90^{\circ} \mathrm{C}$.

\subsection{Characterization of the rubber compounds:}

Mooney viscosities, $\mathrm{ML}(1+4)$ at $100^{\circ} \mathrm{C}$ were measured using a large rotor Mooney viscometer, MV 2000E, Alpha technologies, USA, following ASTM D 1646. Cure characteristics of the compounds were determined using a Moving die rheometer (P-MDR, Alpha technologies, USA) following ASTM D 5289. Isothermal curing condition was maintained at $145^{\circ} \mathrm{C}$ for 60 min. Moulding of the compounds was performed by compression molding following ASTM D3182 in a hydraulic press (Hind Hydraulics, India). The curing This publication is licensed under Creative Commons Attribution CC BY. 
condition maintained for tensile slabs was $145^{\circ} \mathrm{C}$ for with two times the $t_{c} 90$ values obtained in rheometer, with a moulding pressure of 14.71 MPa. Stress-strain properties of the vulcanizates were checked using Z010 universal testing machine (UTM) from Zwick (UTM, Germany) as per ASTM D412. Dumbbell shaped specimens were used during physical testing (ASTM die - C). Dispersion of nanoclay was studied in a TEM at 200kv acceleration voltage (Talos-S, FEI, USA). All pictures were taken at 1 micron magnification. Samples were cryomicrotomed (Leica Ultracut UCT) at $-100^{\circ} \mathrm{C}$ to a specimen thickness of $100 \mathrm{~nm}$ prior to analysis. Air permeability was tested in Prolific Gas Permeability Tester as per IS 3400-21 method.

\section{RESULTS AND DISCUSSION}

\subsection{Cure Characteristics Measurement:}

Vulcanization parameters are reported in Table 2. The increase in both minimum $\left(\mathrm{M}_{\mathrm{L}}\right)$ and maximum torque $\left(\mathrm{M}_{\mathrm{H}}\right)$ values in the experimental compounds signifies higher filler networking in presence of nanoclays. Although there is no significant change in the scorch safety time $\left(t_{s} 2\right)$ in between the experimental compounds, however the optimum cure time $\left(t_{c} 90\right)$ has been increased compared to the control. The nanoclays are primarily consists of silicate layers which makes them acidic in nature. Therefore, the curing time has increased in the clay containing compounds. The slowness in the curing is more significant in Sepiolite clay whereas for Cloisite 30B, the effect is less pronounced. Perhaps the presence of organic amines as modifiers in Cloisite 30B somewhat neutralizes the acidity of the medium. As a result, the curing reaction was facilitated.

Table 2: Cure characteristics of the compounds

\begin{tabular}{|c|c|c|c|c|c|}
\hline Rheometric properties & Control & SP-2 & 30B-2 & SP-4 & 30B-4 \\
\hline$M_{L}$ (lb.in.) & 1.24 & 1.32 & 1.25 & 1.47 & 1.41 \\
\hline $\mathbf{M}_{H}$ (lb.in.) & 4.52 & 4.76 & 4.71 & 4.97 & 5.10 \\
\hline $\mathbf{t}_{\mathrm{s}} 2(\min )$ & 17.36 & 18.36 & 16.78 & 19.08 & 18.2 \\
\hline $\mathbf{t}_{\mathbf{c}} 10$ (min) & 5.63 & 5.36 & 5.66 & 5.43 & 5.33 \\
\hline$t_{c} 40$ (min) & 13.08 & 14.18 & 13.66 & 14.34 & 13.91 \\
\hline $\mathbf{t}_{\mathrm{c}} \mathbf{5 0}$ (min) & 14.94 & 16.52 & 15.85 & 16.81 & 16.23 \\
\hline tc90 (min) & 28.74 & 32.97 & 29.89 & 34.11 & 31.51 \\
\hline
\end{tabular}

\subsection{Studies on Mechanical Properties:}

Mechanical properties are represented in Fig. 3. The mechanical properties of the compounds were expressed in terms of modulus, which is stress at specific elongations such as 50\%, 100\% 200\% and 300\% strains, ultimate tensile strength, elongation at break and hardness. It was observed that the addition of nanoclays increases both modulus and hardness of the compounds. This was probably due to the positive interaction between the rubber and nanoclays in presence of carbon black fillers [10]. Also, the mechanical strength the composite increases with increase in the dosage of nanoclays from $2 \mathrm{phr}$ to $4 \mathrm{phr}$. The reinforcement effect is more evident for Cloisite 30B as compared to Sepiolite clay. The possible reason being the additional presence of organic amine modifier in the Cloisite 30B has interacted with the polymer and thus improving the polymer filler interaction which has resulted in the overall improvement in the mechanical properties. 

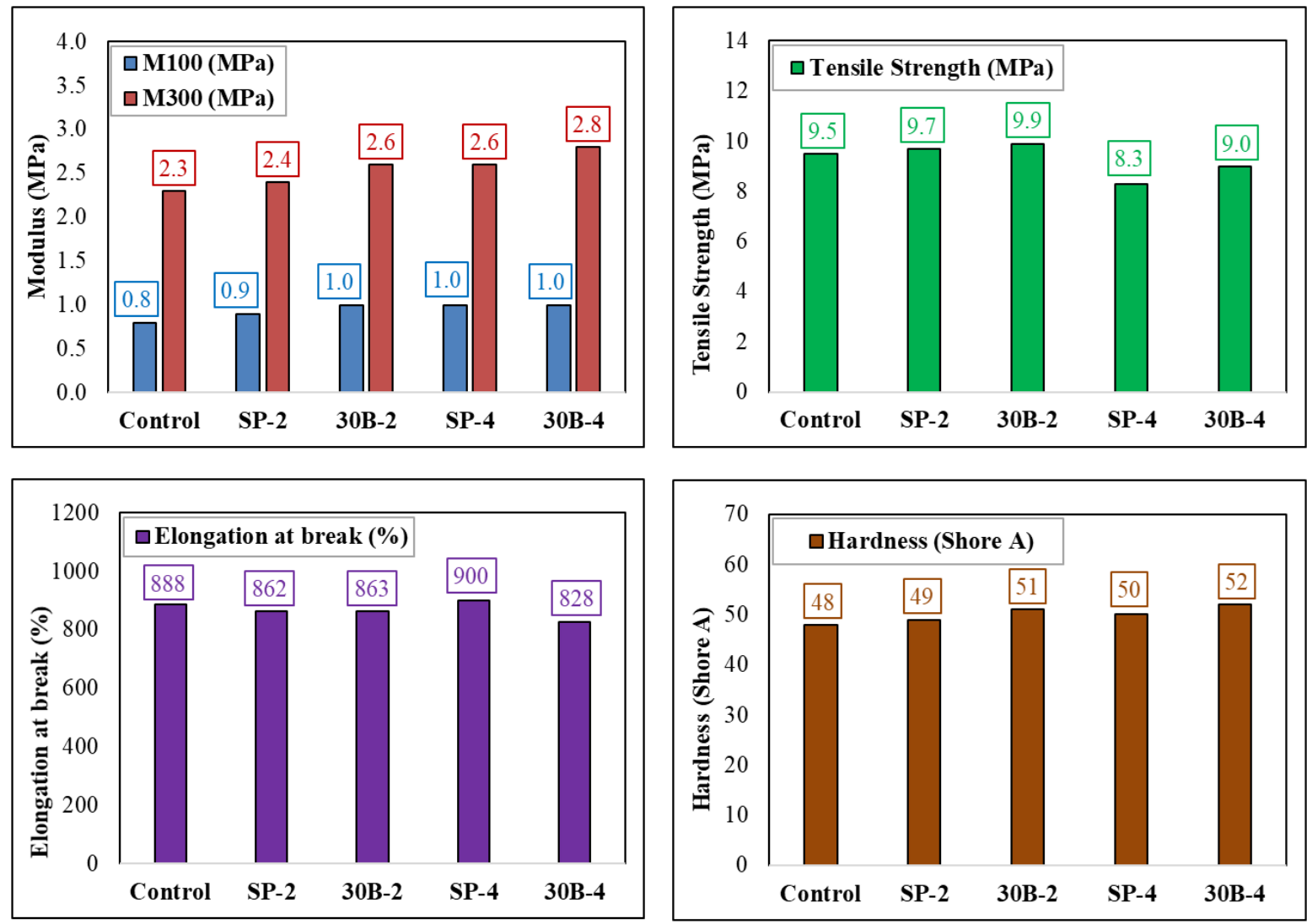

Figure 3: Mechanical properties of the compounds

\subsection{TEM Analysis:}

Dispersion of the nanofillers were studied under TEM and the images are shown in Fig. 4. Both the experimental compounds SP-4 and 30B-4 containing $4 \mathrm{phr}$ of nanofillers were considered for TEM study due to the improved occurrence of the clay particles in the matrix. In Fig. 4 (a), it was observed that the Cloisite 30B platelets were well dispersed and exfoliated within the carbon black galleries in the polymer matrix whereas in Fig. 4 (b), clay platelets of Sepiolite were found to be agglomerated in the matrix. Cloisite 30B being a modified organoclay, has edge over conventional layered silicate clays like Sepiolite when it comes to the dispersion in rubber. The presence of organic amines in Cloisite 30B improves the interaction with polymers and thus eases the clay dispersion process [11]. Sepiolite is primarily an inorganic magnesium silicate clay which has poor compatibility with rubber and strong inter layer interaction between the stacked clay layers, hence it is inferior in dispersion than Cloisite 30B. 


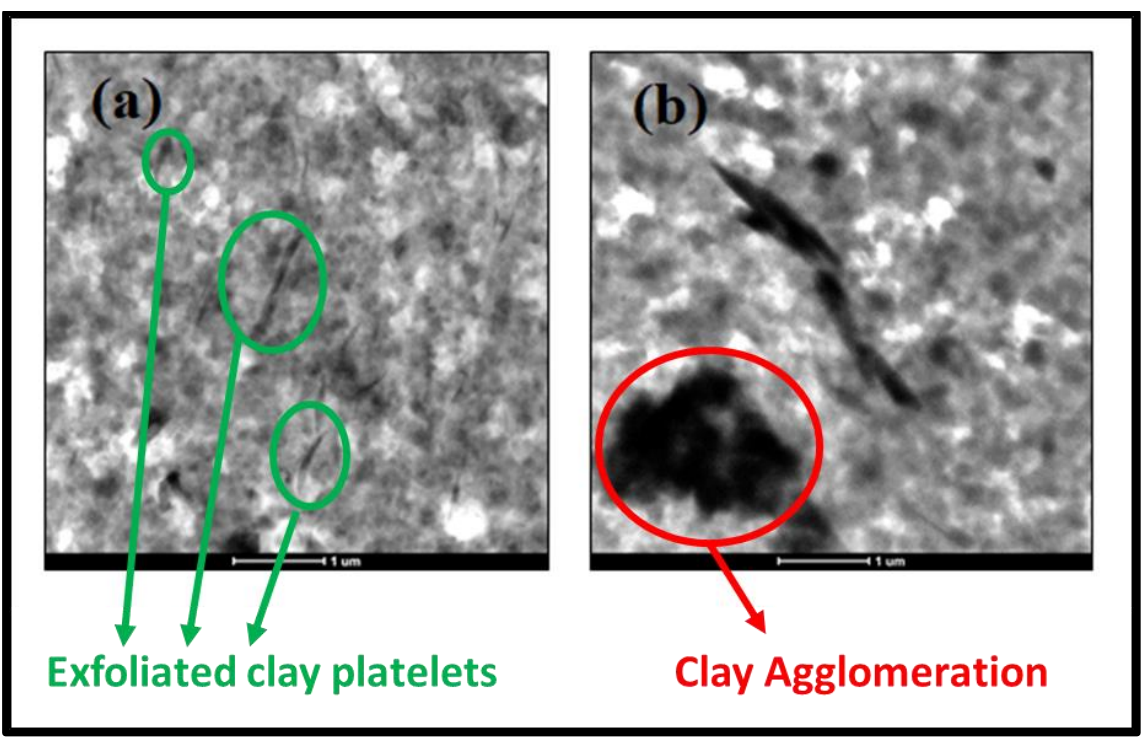

Figure 4: Representative TEM images of (a) 30B-4 and (b) SP-4 respectively

\subsection{Air Impermeability Measurements:}

Air impermeability data are shared in Fig. 5. It was noticed that with Sepiolite clay there was no significant change (3\% improvement) in air impermeability. However, with Cloisite 30B at 2 phr loading, the improvement was 5\% and that with 4 phr loading, the improvement was $12 \%$. This is mainly due to the better dispersion of Cloisite 30B [8] as compared to Sepiolite as observed time and again. Sepiolite on the other hand had a tendency for agglomeration, therefore the dispersion is poor. Hence the property enhancement is not significant.

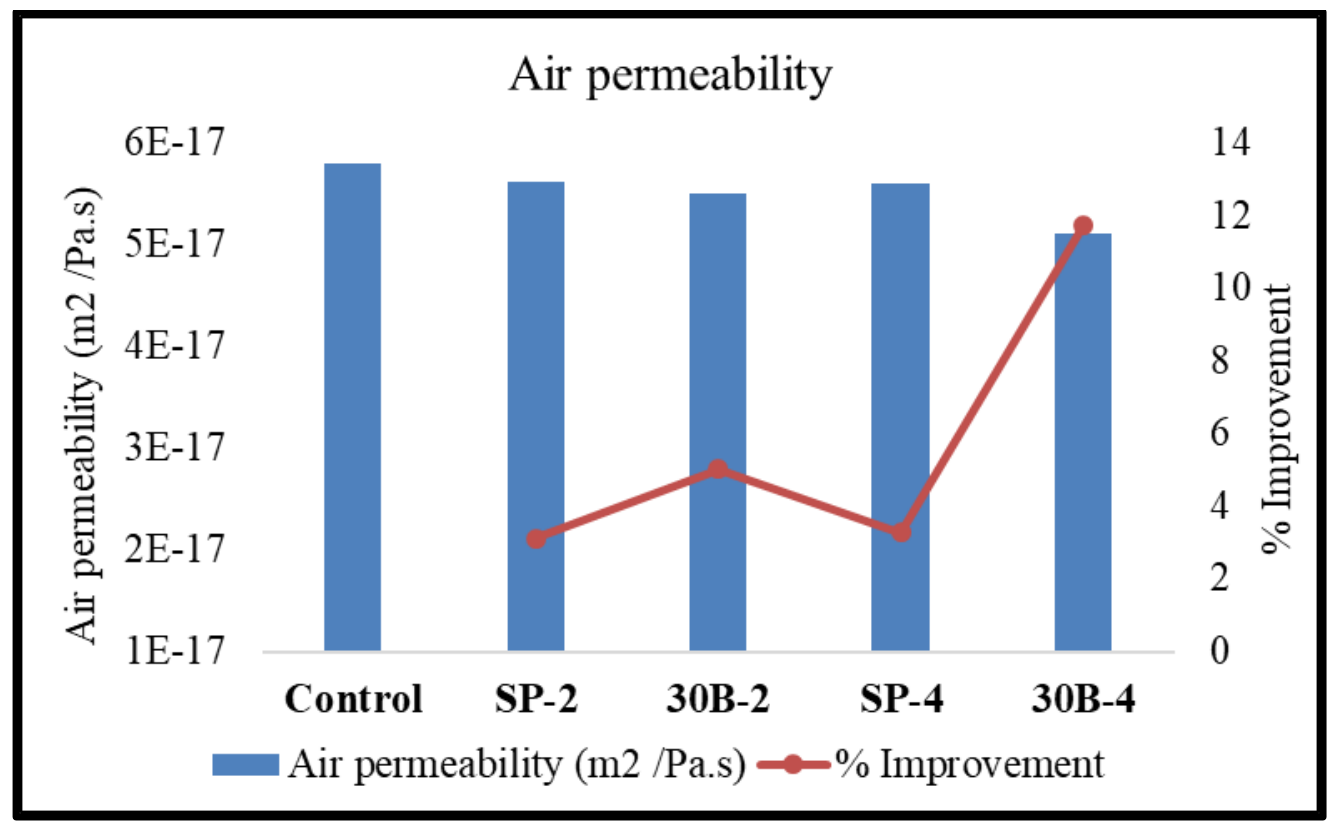

Figure 5: Air-permeability chart of the compounds

\subsection{Inner liner Thickness Reduction Study:}

Based on the encouraging results obtained with Cloisite 30B in inner liner, it was further decided to reduce the thickness of the inner liner in order to maintain the air retention so as to get the cost reduction benefit. In the thickness reduction study, air retention of the specimen with different thickness were measured. From the air impermeability values, a linear fit was made with a correlation coefficient 
of 0.967 which is shown in Fig. 6. From the linear equation, it was calculated that in the experimental compounds to maintain the air retention same as that of the control, thickness can be reduced up to $56 \%$.

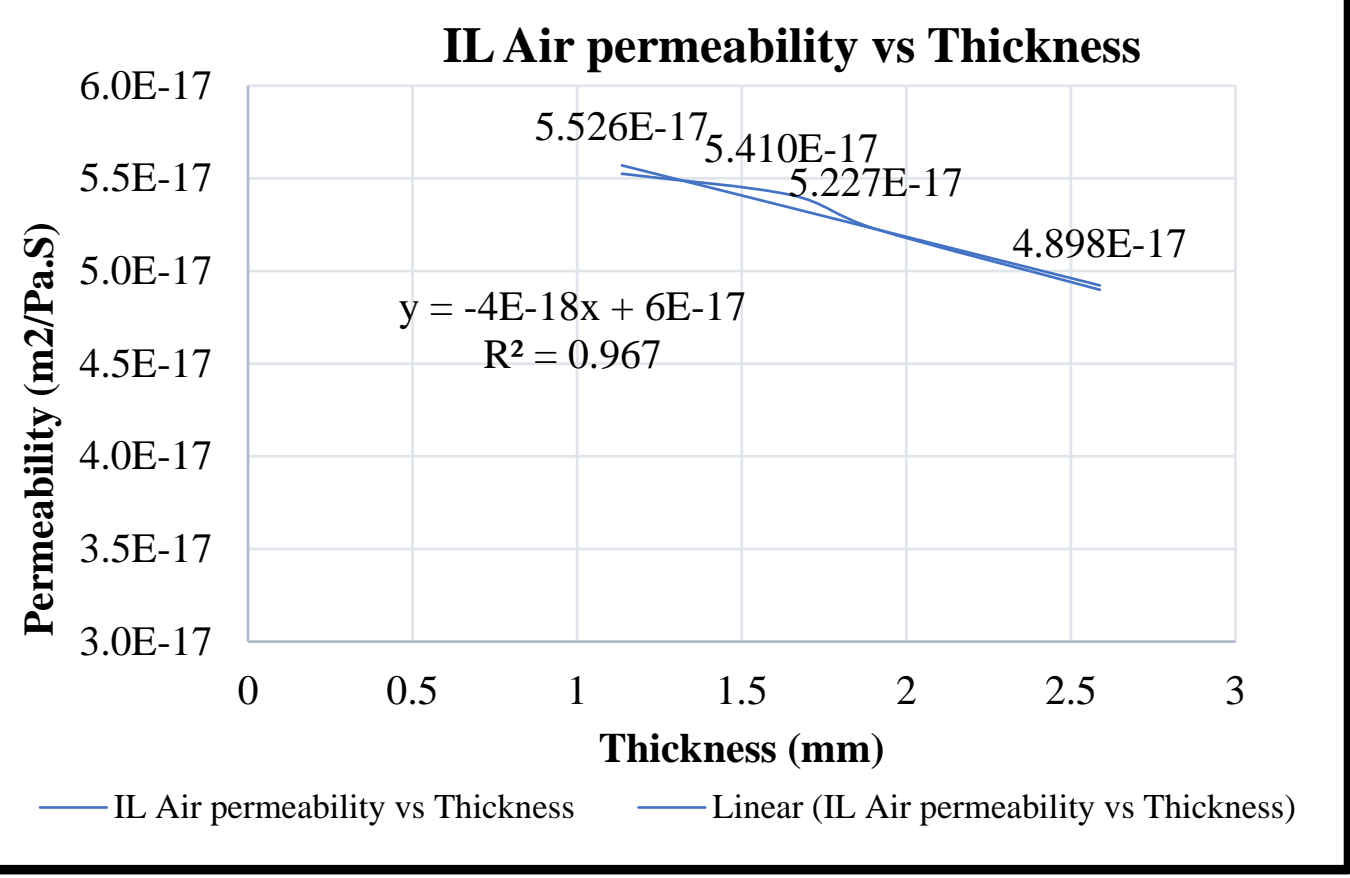

Figure 6: Correlation plot for air impermeability with inner liner thickness of the compounds

\section{CONCLUSIONS}

From the above experiment it can be concluded that the organically modified nanoclay Cloisite 30B has the potential to improve the barrier properties of the tyre inner liner compounds without affecting the mechanical properties. It was evident that with 4 phr clay dosage, air impermeability can be improved up to $12 \%$. Based on the improved air retention, the thickness can be reduced up to $56 \%$ in order to maintain the air impermeability same as that of the control compound.

\section{Acknowledgement}

The authors would like to thank HASETRI management for their kind permission to publish this work.

\section{REFERENCES}

[1] S. Pavlidou and C. D. Papaspyrides, "A review on polymer-layered silicate nanocomposites," Prog. Polym. Sci., vol. 33, no. 12, pp. 1119-1198, 2008, doi: 10.1016/j.progpolymsci.2008.07.008.

[2] L. Bokobza, "Multiwall carbon nanotube elastomeric composites: A review," Polymer (Guildf)., vol. 48, no. 17, pp. 49074920, Aug. 2007, doi: 10.1016/j.polymer.2007.06.046.

[3] H. B. Kaybal, H. Ulus, and A. Avci, "Influence of Nano-CaCO3 Particles on Shear Strength of Epoxy Resin Adhesives," Uluslararası Muhendis. Arastirma ve Gelistirme Derg., pp. 29-35, 2017, doi: 10.29137/umagd.371119.

[4] C. A. Clausen, S. N. Kartal, R. A. Arango, and F. Green, "The role of particle size of particulate nano-zinc oxide wood preservatives on termite mortality and leach resistance," Nanoscale Res. Lett., vol. 6, pp. 1-5, 2011, doi: 10.1186/1556-276X6-427. 
[5] R. Scotti et al., "Shape controlled spherical (0D) and rod-like (1D) silica nanoparticles in silica/styrene butadiene rubber nanocomposites: Role of the particle morphology on the filler reinforcing effect," Polymer (Guildf)., vol. 55, no. 6, pp. 14971506, 2014, doi: 10.1016/j.polymer.2014.01.025.

[6] M. Arroyo, M. A. López-Manchado, and B. Herrero, "Organo-montmorillonite as substitute of carbon black in natural rubber compounds," Polymer (Guildf)., vol. 44, no. 8, pp. 2447-2453, 2003, doi: 10.1016/S0032-3861(03)00090-9.

[7] A. Kumar, S. Modi, A. Panwar, D. Schmidt, C. M. F. Barry, and J. L. Mead, "Highly impermeable nanocomposites of brominated butyl rubber with modified montmorillonite clay," Rubber Chem. Technol., vol. 87, no. 4, pp. 579-592, 2014, doi: 10.5254/rct.14.86929.

[8] Y. Di, S. Iannac, L. Sanguigno, and L. Nicolais, "Barrier and mechanical properties of poly(caprolactone)/organoclay nanocomposites," Macromol. Symp., vol. 228, pp. 115-124, 2005, doi: 10.1002/masy.200551010.

[9] K. Banerjee et al., "Effect of pre-mastication on dispersion of nanoclay in presence of carbon black in an inner liner compound: Studies on physicomechanical and functional properties," Polym. Eng. Sci., vol. n/a, no. n/a, Jan. 2021, doi: https://doi.org/10.1002/pen.25639.

[10] S. Praveen, P. K. Chattopadhyay, P. Albert, V. G. Dalvi, B. C. Chakraborty, and S. Chattopadhyay, "Synergistic effect of carbon black and nanoclay fillers in styrene butadiene rubber matrix: Development of dual structure," Compos. Part A Appl. Sci. Manuf., vol. 40, no. 3, pp. 309-316, 2009, doi: 10.1016/j.compositesa.2008.12.008.

[11] S. Kumar, G. B. Nando, S. Nair, G. Unnikrishnan, A. Sreejesh, and S. Chattopadhyay, "Effect of organically modified montmorillonite clay on morphological, physicomechanical, thermalstability, and water vapor transmission rate properties of BIIR-CO rubber nanocomposite," Rubber Chem. Technol., vol. 88, no. 1, pp. 176-196, 2015, doi: 10.5254/rct.14.85996. 